\title{
Effects of the inhalation of particulate matter in the central nervous system
}

\author{
Efectos de la inhalación de material particulado en el sistema nervioso central
}

Norma Barragán-López ${ }^{a}$

\begin{abstract}
:
The most common pollutant of the air that surrounds us in the atmosphere is Particulate Matter (PM), which is a heterogeneous mixture suspended as aerosol droplets we breathe. Studies in animals and humans indicate that this particulate material can pass from the upper respiratory tract and reach the brain through the olfactory nerve, or reach the lungs and pass into the bloodstream and affect other organs or coagulation mechanisms, which may cause vascular accidents, heart attacks, chronic lung diseases or cancer. In developing countries, in 2012, there were a total of 7.3 million deaths associated with environmental causes; and of them, most are attributed to air pollution specifically. Upon reaching the brain, the particulate material produces molecular, cellular, histological and pathophysiological alterations that can lead to the exposed individual having the risk of seeing their cognitive functions affected and if this progresses, develop dementia. The most common type of dementia is Alzheimer's Disease, which constitutes a major public health problem. The objective of this text is a search of studies in animals and in people about the negative effects of the inhalation of particulate material on the brain and its functions, and the possibility of reaching degenerative states such as dementia.
\end{abstract}

\section{Keywords:}

Particulate matter, central nervous system, Alzheimer's disea se, brain

\section{Resumen:}

El más común de los contaminantes del aire que nos rodea en la atmósfera es el Material Particulado (PM), que es una mezcla heterogénea suspendida como gotas en aerosol que respiramos. Estudios en animales y en humanos, indican que este material particulado puede pasar del tracto respiratorio superior y llegar hasta el cerebro a través del nervio olfatorio, o llegar a los pulmones y pasar a la circulación sanguínea y afectar otros órganos o los mecanismos de coagulación, con lo que pueden causar accidentes vasculares, infartos, neumopatías crónicas o cáncer. En los países en vías de desarrollo en 2012 ocurrieron un total de 7,3 millones de muertes asociadas a causas medioambientales; y de ellas, la mayoría se atribuyen a contaminación del aire específicamente. Al llegar al cerebro, el material particulado produce alteraciones moleculares, celulares, histológicas y fisiopatológicas que pueden llevar a que el individuo expuesto tenga el riesgo de ver afectadas sus funciones cognitivas y si esto progresa, desarrollar demencia. El tipo más común de demencia es la Enfermedad de Alzheimer, que constituyen un importante problema de salud pública. El objetivo de esta investigación es realizar una búsqueda de estudios en animales y en población acerca de los efectos negativos que tiene la inhalación del material particulado sobre el cerebro y sus funciones, y la posibilidad de llegar a estados degenerativos como la demencia.

\section{Palabras Clave:}

Material particulado, sistema nervioso central, enfermedad de Alzheimer, cerebro

${ }^{a}$ Corresponding author, Consultorio Particular. Plaza Independencia, 101-Altos, Pachuca, Hidalgo, México, https://orcid.org/0000-0003-43700616,Email:normabl_2013@outlook.es 


\section{INTRODUCTION}

The atmosphere is the gaseous layer that surround s the planet and any alteration that occurs has as a consequence and great effect on living beings and the gases present play a very important role in meteorological processes, erosion and the hydrological cycle; this is why the balance between them is fundamental. The atmosphere also maintains the temperature of the earth, avoiding abrupt changes in it and filters the radiation that would be dangerous for life on earth. ${ }^{1}$

The most common pollutant of the air that surrounds us in the atmosphere is Particulate Matter (PM), which is a heterogeneous and complex mixture of dust, various organic compounds, acids, metals and microorganisms in the form of particles extremely small suspended as aerosol droplets. ${ }^{2,3}$ The other air pollutants found most frequently are sulfur dioxide (SO2), nitrogen dioxide (NO2), ozone (O3), carbon monoxide $(\mathrm{CO})$, and carbon dioxide $(\mathrm{CO} 2)^{4}$

Studies in animals and humans indicate that this particulate material can pass from the upper respiratory tract to brain tissue and cause inflammation, which is pathological evidence and this can cause damage in cognitive processes. ${ }^{5,6}$

Researchers have classified the particles by their diameter; those that measure between 2.5 and $10 \mu \mathrm{m}\left(\mathrm{PM}_{2.5-10}\right)$ are called "coarse", less than $2.5 \mu \mathrm{m}$ "thin" and less than $0.1 \mu \mathrm{m}$ "ultrafine".

The particulate material can come from two types of sources: natural and anthropogenic. In nature, phenomena such as earthquakes, forest fires, volcanic eruptions and sand storms are carried out, which can disperse particles and together with dust and pollen are suspended in the air we breathe. However, there are those caused by man's activity on earth (motor vehicle emissions, industrial, waste incineration, power generation, fuel combustion) which has worried scientists around the world to observe the possible negative effects that may have on the health of the beings that inhabit the planet. In Mexico, according to the Ministry of Environment and Natural Resources (SEMARNAT), $20.7 \%$ of the pollutants are from natural sources and $79.3 \%$ is produced by the human being with its daily dynamics. ${ }^{1,7}$

Pollution is currently present in almost all inhabited regions of the world, however, developing countries are the most affected by contamination, where in 2012 there were a total of 7.3 million associated deaths to environmental causes; and of them, most are attributed to air pollution specifically. In the region of the Americas, 847,000 deaths occurred due to this cause. ${ }^{8}$
The objective of this manuscript is a search of studies in animals and in people about the negative effects of the inhalation of particulate material on the brain and its functions, and the possibility of reaching degenerative states such as dementia. Information found on particulate material of any diameter and coming from any source was included.

There are subgroups of the general population that can be considered to be at higher risk, such as children, older adults, people with previous illnesses (mainly respiratory or cardiovascular) or low socioeconomic status. ${ }^{4}$

The pathologies that are most associated with environmental contamination are cancers, chronic lung diseases and cerebral vascular accidents, which currently constitute almost two thirds of the total deaths because of environmental causes, ${ }^{8}$ which is alarming because it will add to the burden of morbidity of the rest of chronic diseases that constitute a problem for public health in the territories of the world.

With respect to the respiratory tract, the PM has frank effects when coming into direct contact with these airborne agents, mainly causing inflammation and can alter the defense mechanisms of these routes or they can aggravate the evolution of pathologies already in course. Extrapulmonary effects of PM can be found, there is the possibility that they also directly affect the heart or the coagulation mechanisms, which can cause vascular accidents or heart attacks. ${ }^{4}$

All of the above become more important when analyzing that the molecular, cellular, histological and pathophysiological alterations produced by contaminant particles in the brain can cause cognitive deficit and ultimately, dementia, which is fatal. ${ }^{9,10}$

\section{HOW DOES THE PARTICULATE MATTER GETS INTO THE BRAIN?}

There are several studies that have currently analyzed whether the inhalation of PM can cause damage to the central nervous system (CNS), the possible mechanisms by which the finest particles can reach this organ and what effects it has on this tissue in the short, medium and long term. ${ }^{11}$

In a study carried out with mice, it is illustrated how the particulate material can inflame the brain of living beings that breathe it by 2 considerable routes. In the first one, the compound s of the thick PM reach the airways, come into contact with the respiratory tissue and originate the production of reactive oxygen species and activate molecular signaling cascades that 
give way to inflammation, whose factors travel through the bloodstream and go through the blood-brain barrier. A second possible route is that of the olfactory nerve, upon inhaling, the particles are deposited in the respiratory epithelium and reach the respiratory bulb through the neuronal axons and could infiltrate contiguous regions of the brain. ${ }^{12}$

In another investigation in mice, 3 models were carried out: in vivo, in vitro and ex vivo; and as a result they found that prolonged in vivo exposure to nanometric PM induces rapid oxidative stress and inflammation in the olfactory epithelium and olfactory bulb. In the in vitro model, it also induces oxidative stress and inflammation is observed in olfactory epithelial cells cultured for this study. ${ }^{9}$

The first nerve cells that react to air pollutants that were inhaled are the olfactory sensory neurons of the epithelium in the respiratory tract that are directly exposed to the external environment. When studying the tissues they observed that neurodegenerative changes arose later in the olfactory epithelium. The cerebral cortex and the cerebellum also showed an increase in Tumor Necrosis Factor $\alpha$ (TNF $\alpha)$, more slowly. These findings lead to the hypothesis that the increase in TNF $\alpha$ and other cytokines may be a factor that contributes in part to the development of cognitive deficits in exposed subjects. ${ }^{9}$

Another important pathological change generated by the particles of pollution that are inhaled is the expression of genes related to cancer, as demonstrated by the experimental study conducted in one hundred laboratory rats, divided into groups of animals with short exposure ( 2 weeks), intermediate (1 to 3 months) and long exposure (1 year); and separated by each type of PM analyzed and others more to filtered air as controls. ${ }^{12}$

Because according to the size of the particle is related to different health damage or different organs that are affected, this study considered essential to separate the gross particulate material from thin, so they used a material impactor to separate them and then the fine particles were subdivided into PM $<2.5$ and aerosols Ultra Fine Particulate Material (UFPM). ${ }^{12}$

Regarding the size of the particle, PM from 2.5 to $10 \mu \mathrm{m}$, triggers inflammation and the expression of oncogenes in the brains of rats. The coarse particulate material caused upregulation of inflammation and genes related to cancer. They observed that these changes in short-term exposure were not significant, however, in the medium term exposure, these positive regulation processes appeared significantly, inflammation and tumorigenesis genes were expressed transiently, since during the follow-up process occurred downregulation. ${ }^{12}$
Other authors have also found inflammatory effects of the particulate material in other organs and tissues. ${ }^{13}$

The researchers argue that each type of PM has a particular toxicological characteristic which will determine its specific interaction with different molecules and will affect different organs differently. The research of these authors analyzes the expression of genetic information in nervous cells that may be affected by exposure to contamination ${ }^{12}$, which could have an important implication in molecular changes that result in brain disease or neurodegenerative disorder. ${ }^{14}$

A fundamental aspect highlighted by the authors is the possibility that these findings are unique to the region studied, since it depends strongly on the composition of air pollutants in each region, so the importance of more studies on the biology of tissue damage due to air pollution, which can guide political efforts to reduce the levels of this type of pollution. ${ }^{12}$

In a pilot study in healthy young dogs, which were exposed to particulate material, changes were identified in the olfactory epithelium of the exposed dogs, also in the lungs in the form of chronic mononuclear cell infiltrates and PM-filled macrophages around the vascular structures and inside the alveolar spaces. ${ }^{14}$

Another research conducted in Mexico analyzed samples of prefrontal white matter in healthy young dogs living in Mexico City and in a cohort of children and adolescents from the same city with prefrontal samples by autopsy versus clean air controls (dogs and children). ${ }^{15}$

This analysis yielded very valuable results, since ultrafine particles were identified in mitochondria, basal membranes, axons, and dendrites of the prefrontal matter of the brain, as well as anomalies in the endothelial binding complexes, microhemorrhages, accumulation of perivascular lipids and abnormalities in the basal cerebrovascular membranes. ${ }^{15}$

Research in this area has also been carried out in humans since millions of people started living in the megacities of the world; environmental air pollution is a serious public health problem. The smallest particles are the most harmful; due to their size they reach deeper into the respiratory tract and from there to directly translocate into the brain. ${ }^{6}$

Another human investigation was the cohort conducted in the New England region, from 1998 to 2001, involving 943 people, who had no history of dementia, stroke or transient ischemia, 60 years of age or older. ${ }^{16}$ 
At the end of the study, they found that relatively low levels of particulate matter in air pollution in an urban area can accelerate atrophic changes and small vessel disease in older adults, however more studies are needed. ${ }^{16}$

To predict the daily concentration of $\mathrm{PM}_{2.5}$ in New England, a moderate resolution image spectroradiometer was used for aerosol optical density measurements derived from a satellite. According to the class of characteristics of the Census in the United States, the residential proximity to the nearest roads in the studied region was determined. ${ }^{16}$

A higher $\mathrm{PM}_{2.5}$ was associated with a smaller Total Brain Volume (TCBV) and 1.46 times (95\% confidence interval [CI], 1.10 to 1.94) higher odds of Covert BrainInfarct (CBI). An increase of 2 $\mu \mathrm{g} / \mathrm{m} 3$ in $\mathrm{PM}_{2.5}$ was associated with a difference of $0.32 \mathrm{U}$ in TCBV (95\% CI, -0.59 to -0.05). There was no clear association pattern between $\mathrm{PM}_{2.5}$ and Hippocampal Volume (HV), White Matter Hyperintensity Volume (WMHV) or Extensive White Matter Hyperintensity Volume (EXT-WMHV). ${ }^{16}$

The findings in this study support the theory of chronic exposure to air pollution and its association with structural brain changes that can lead to cognitive decline. The authors mention that these results can not be generalizable to other populations due to some aspects, like the fact that most of the participants are white skinned. The strengths that it highlights are that it is a study with a relatively large sample, based on the community, inclusive of both sexes, encompasses findings from imaging studies and estimates individual levels of exposure. ${ }^{16}$

One study analyzed this question from another perspective, using markers in CNS imaging studies. In a sample of older adults, markers of neurodegeneration or subclinical cerebral vascular disease with Magnetic Resonance Imaging (MRI) were evaluated to quantify their association with long-term exposure in the past to particulate material. They did not find associations between the cumulative exposure to PM and markers in magnetic resonance of cerebrovascular disease, so there is a possibility that when carrying out focused studies in certain geographical points, sometimes the associations between the contamination of the air and the negative effects on brain tissue cannot be appreciated, however, studies with greater geographical breadth can better capture the combination of the effects on the health of the central nervous system. ${ }^{17}$

They accept some limitations, such as the inability to measure exposure to indoor pollution. The impossibility of discarding regional variations in the prediction and precision of the model can complicate the validation in the comparison of site-specific effects. ${ }^{17}$

\section{THE ALZHEIMER TYPE DEMENTIA AS A RELEVANT AFFECTION OF THE CENTRAL NERVOUS SYSTEM}

Dementia is a broad term that includes the description of various diseases and conditions that arise when neuronal cells do not function properly or die. This can lead to alterations in memory, behavior and other functions. It is fatal in the end. ${ }^{10}$

Alzheimer's disease (AD) is a type of dementia. It has three distinctive histopathological markers that affect the cerebral synapse, which are: the alteration of the processing of the amyloid precursor protein, beta-amyloid plaques are generated and also the hyperphosphorylation of tau observed when analyzing neuronal tissue. ${ }^{11}$

Alzheimer's disease and other dementias, constitute an important public health problem, ${ }^{18}$ it is estimated that 70 to $80 \%$ of cases of dementia are of this type, which makes it the most common. It is a multicausal disease that was identified more than a century ago, although it has only been about 3 decades since the interest in research about its causes, risk factors, signs, symptoms and treatment has increased. ${ }^{10}$

There are not many studies on risk factors for dementia due, in part, to the broad spectrum that is covered for its understanding and due to the difficulty to make objective evaluations about accumulated environmental exposure; however, it is known that environmental factors play a very important role in the development of this pathological state. Advanced age, family history, APOE $\varepsilon 4$ gene, mild cognitive impairment, cardiovascular disease risk factors, education, social and cognitive engagement, Traumatic Brain Injury (TBI) are other identified risk factors for Alzheimer's disease. ${ }^{5}$

The first signs of Alzheimer's type dementia often begin with the inability to remember new information, depression can also occur. In the late stages there are alterations in judgment, behavior, confusion, disorientation and finally difficulty to walk, talk and swallow food. It is progressive, and in the advanced stages people need assistance for daily activities such as personal hygiene and to feed themselves. Having little mobility, they can more easily develop infections. ${ }^{10}$

Chen et al. ${ }^{18}$ noted that exposure to ambient air pollution, even at relatively low levels, is associated with a high incidence of dementia. This study was carried out in Ontario, Canada, which is one of the places with the lowest rates of air pollutants in the world. 
In this article authors conducted a cohort study to investigate whether exposure to common air pollutants are associated with the diagnosis of dementia and followed up from 2001 to 2013, to $2,066,639$ subjects who were initially in the group of 55 to 85 years old and did not have a medical diagnosis of dementia. ${ }^{5}$

One limitation in this cohort study was the failure to identify the number of possible cases of undiagnosed dementia, and one of its most notable strengths is the size of the population it covers, since it includes the entire population of older adults in Ontario. ${ }^{5}$

In a case-control study in Taiwan, the case group included 483 patients with dementia from neurology clinics at three teaching hospitals in the north of the city between 2007 and 2010. Five hundred and sixty five healthy controls were recruited from the health check-up program in seniors and volunteers of the hospital during the same period of time. The subjects of both groups were 60 years old or older. ${ }^{5}$

One of the results obtained during this investigation was to observe that the highest tertile exposure to $\mathrm{PM}_{10}$ was significantly associated with an increased risk of $\mathrm{AD}$, although many more data were also found to have an impact on ozone exposure and other variables. One of the most relevant points of discussion in this scientific document is that it is mentioned that although there are previous studies that relate the exposure to particulate material from vehicular traffic with cognitive deterioration in the elderly, many are not able to give a wide explanation of the association that exists between air pollutants and the risk of developing dementia. ${ }^{5}$ This is consistent with what was found by other researchers. ${ }^{15}$

This study accepts many strengths but also limitations, including the fact that it only evaluates 2 types of air pollutants, ozone and $\mathrm{PM}_{10}$, because it is one of the components that had the most data available in the long term. Another important limitation is the age of the participants, who are very old, on average 79 years old and may give rise to a survival bias. ${ }^{5}$

They conclude that the investigation yields a clear observation that had not been previously reported; the dose-response relationship between $\mathrm{PM}_{10}$ and the risk of $\mathrm{AD}$ and small-vessel vascular dementia; and that further future studies are required to continue exploring the role of air pollutants in dementias. ${ }^{5}$

In an important study, Calderon-Garciduenas et al. ${ }^{19}$ carried out an analysis in two cities of Mexico considered highly contaminated, with samples obtained by necropsy of inhabitants of these zones for a long time, and compared them with samples from 5 small cities with low levels of air pollution.
Part of the results showed that people living in highly contaminated places presented data of chronic inflammation in the respiratory tract. They highlight as part of the results that amyloid plaques or entangled fibers were not found in the histopathological study, as is classic in Alzheimer's dementia, however this is expected to some extent due to the relatively young average age of the study subjects; however, finding these signs not fully evidenced does not mean that there are no pathological changes, because the establishment of the disease may take many years. ${ }^{19}$

Several investigations have used animal experimentation to clarify questions about Alzheimer's disease, as it is the case of the pilot study, using a model of long-term suspension particle inhalation in mice to mimic exposure to the levels of $\mathrm{PM}_{2.5}$ of the National Ambient Air Quality Standards (NAAQS) and quantified changes in the state of inflammation of the brain. In the long-term follow-up of the animals, at 9 months, they observed that inflammatory brain alterations do occur and that they can promote Alzheimer's disease (AD), which indicates that it is a reasonable time to observe important changes. They demonstrated that long-term exposure to particles suspended in the air modestly increases the levels of cytokines, $\mathrm{A} \beta$ and COX$1 / 2$ associated with early pathology type EA in the brain of rodents. Among other results, they found that it did not affect tau hyperphosphorylation. They conclude that this study provides a reliable model to replicate inhalation exposure conditions to particulate matter suspended in a controlled manner and that studies such as this can be useful to address prevent environmental risk factors. ${ }^{11}$

In the analysis carried out by Kilian and Kitazawa ${ }^{20}$ on several experiments performed on animals, the findings allow them to make a possible connection between chronic exposure to PM and the development of dementias such as AD. It is emphasized that the difference in concentration and composition of air pollutants vary according to time and place, which may explain the divergences found in the different studies in the world.

More studies are considered necessary that include the genetic risk factors, and to observe if they are determinant for the development of the disease and if the exposure to particulate material can be linked in a specific way to AD in the absence of these other elements, since they can act as confusers, it is necessary to continue with the production of new evidence that shows the association between dementia and particulate matter to base political actions directed at risk populations. ${ }^{20}$

\section{CONCLUSION}


There is sufficient evidence to be able to associate the particulate matter as a risk factor and possible causal agent of alterations to the cerebral system when inhaled. These alterations, such as the appearance of factors like chronic inflammation, expression of oncogenes, and histopathological features (like those observed in the brains of people with dementia) should be sufficient to support environmental policies existing and generate new ones that are better and contribute to the recovery of the environment in which the living beings of this planet have the right to develop themselves.

Transsectoral participation is necessary since, in Mexico and the world, this type of policy does not only correspond to one sector but also health, environment, agriculture, energy, transport, housing, among others. ${ }^{21}$ This will also increase the quality of life and reduce health costs.

\section{REFERENCES}

1. Secretaría de Medio Ambiente y Recursos Naturales. Calidad del aire: una práctica de vida. [Document on the Internet]. 2013. [cited 2019, march 5]; Available from: http://biblioteca.semarnat.gob.mx/janium/Documentos/Ciga/Li bros2013/CD001593.pdf

2. Anderson JO, Thundiyil JG, Stolbach A. Clearing the air: A review of the effects of particulate matter air pollution on human health. J. Med. Toxicol. 2012; 8(2):166-175

3. Wright JC, Ding Y. Pathophysiological effects of particulate matter air pollution on the central nervous system. Environ. Dis. 2016; 1(3):85-9.

4. Chen B, Kan H. Air pollution and population health: a global challenge. Environ. Health Prev. Med. 2008; 13(2):94-101.

5. Yun-Chun W, Yuan-Chien L, Hwa-Lung Y, Jen-Hau C, Ta$\mathrm{Fu} \mathrm{C}, \mathrm{Yu} \mathrm{S}$, et al. Association between air pollutants and dementia risk in the elderly. Alzheimers Dement. 2015; 1(2):220-228.

6. Calderón-Garcidueñas L., Calderón-Garcidueñas A., TorresJardón R. Megacity air pollution and the impact on the central nervous system. FNRE. 2013;3(4):447-456.

7. Wang Y, Xiong L, Tang M. Toxicity of inhaled particulate matter on the central nervous system: neuroinflammation, neuropsychological effects and neurodegenerative disease. J. Appl. Toxicol. 2017; 37(6):644-667.

8. Organización Mundial de la Salud. Cada año mueren 12,6 millones de personas a causa de la insalubridad del medio ambiente. [Document on the Internet]. 2016. [cited 2019 March 5] Available from: https://www.who.int/es/news- room/detail/15-03-2016-an-estimated-12-6-million-deathseach-year-are-attributable-to-unhealthy-environments

9. Cheng H, Saffari A, Sioutas C, Forman HJ, Morgan TE, Finch CE. Nanoscale Particulate Matter from Urban Traffic Rapidly Induces Oxidative Stress and Inflammation in Olfactory Epithelium with Concomitant Effects on Brain. Environ. Health Perspect. 2016; 124(10):1537-1546.

10. Alzheimer's Association. Alzheimer's disease facts and figures 2013. Alzheimers Dement. 2013; 9(2):208-245.

11. Bhatt DP, Puig KL, Gorr MW, Wold LE, Combs CK. A Pilot Study to Assess Effects of Long-Term Inhalation of Airborne Particulate Matter on Early Alzheimer-Like Changes in the Mouse Brain. PLoS ONE. 2015; 10(5):1-20.

12. Ljubimova JY, Braubach O, Patil R, Chiechi A, Tang J, Galstyan A, et al. Coarse particulate matter (PM2.5-10) in Los Angeles Basin air induces expression of inflammation and cancer biomarkers in rat brains. Sci. Rep. 2018; 8(1):1-11.

13. Ramanathan Jr. M, London Jr. NR, Tharakan A, Surya N, Sussan TE, Rao X, et al. Airborne Particulate Matter Induces Nonallergic Eosinophilic Sinonasal Inflammation in Mice. Am. J. Respir. Cell Mol. Biol. 2017; 57(1):59-65.

14. Calderon-Garciduenas L, Mora-Tiscareno A, Gomez-Garza G, Carrasco-Portugal Mdel C, Pérez-Guillé B, Flores-Murrieta FJ, et al. Effects of a cyclooxygenase-2 preferential inhibitor in young healthy dogs exposed to air pollution: a pilot study. Toxicol. Pathol. 2009; 37(5):644-660.

15. Calderón-Garcidueñas L, Reynoso-Robles R, VargasMartínez J, Gómez-Maqueo-Chew A, Pérez-Guillé B, Mukherjee PS, et al. Prefrontal white matter pathology in air pollution exposed Mexico City young urbanities and their potential impact on neurovascular unit dysfunction and the development of Alzheimer's disease. Environ. Res. 2016; 146:404-417.

16. Wilker EH, Preis SR, Beiser AS, Wolf PA, Au R, Kloog I, et al. Long-term exposure to fine particulate matter, residential proximity to major roads and measures of brain structure. Clin. Sci. 2015; 46(5):1161-1166.

17. Power MC, Lamichhane AP, Liao D, Xu X, JackJr. CR, Gottesman RF, et al. The Association of Long-Term Exposure to Particulate Matter Air Pollution with Brain MRI Findings: The ARIC Study. Environ. Health Perspect. 2018; 126(2):1-8.

18. Chen H, Kwong JC, Copes R, Hystad P, van Donkelaar A, $\mathrm{Tu} \mathrm{K}$, et al. Exposure to ambient air pollution and the incidence of dementia: A population-based cohort study. Environ. Int. 2017; 108:271-277. 
19. Calderón-Garcidueñas L, Reed W, Maronpot RR, Henríquez-Roldán C, Delgado-Chavez R, CalderónGarcidueñas A, et al. Brain inflammation and Alzheimer's-like pathology in individuals exposed to severe air pollution. Toxicol. Pathol. 2004; 32(6):650-658.

20. Kilian J, Kitazawa M. The emerging risk of exposure to air pollution on cognitive decline and Alzheimer's disease. Evidence from epidemiological and animal studies. Biomed. J. 2018; 41(3):141-162.

21. Riojas-Rodríguez H, Schilmann A, López-Carrillo L, Finkelman J. La salud ambiental en México: situación actual y perspectivas futuras. Salud Publica Mex. 2013; 55(6):638-649. 